\title{
Optimum Design of Uninterruptible Power Supply Systems for Urban and Remote Areas
}

\author{
Yasser Elmasry \\ Electronics and \\ Communication \\ Engineering
}

\author{
Mohamed \\ Nageh \\ Researcher \\ Assistant, \\ Ain Shams Univ.
}

\author{
Wagdy R. Anis \\ Professor, \\ Faculty of Eng. \\ Ain Shams \\ Univ.Cairo, \\ Egypt
}

\author{
Ismail M. Hafez \\ Professor, Faculty \\ of Eng Ain Shams \\ Univ. \\ Cairo, Egypt
}

\author{
A. Refky Mikhail \\ Assistant Professor \\ at National \\ Telecom. \\ Institute cairo, \\ Egypt
}

\begin{abstract}
The power interruption in factories, hospitals, and airports is a critical problem that should be avoided. The solution is uninterruptible power supply (ups) system. Such problem may be solved by introducing solar photovoltaic (PV) or diesel generators (DG)in the ups system. Knowing that the economic problem of providing electrical energy to factories, hospitals, workshops,....etc. may be solved if renewable energy sources are used[1]. In remote areas that have Strong sunlight, where electric utility is not available, photovoltaic (PV) stand-alone system using a lot of batteries is a good solution but it is costly[2]. The system may be a hybrid stand-alone system and a diesel generator combined with PV to supply all critical loads if there is no strong sunlight all over the year in these remote areas. In urban areas, grid connected PV system is a good economical solution. In such a system, during sunshine hours PV system provide a part of its energy to the load and the rest to grid utility, and during the night the load is supplied by grid. The economics of different system will be optimized as follow.
\end{abstract}

\section{Keywords}

Photovoltaic (PV), Batteries , Standby System, Hybrid System, UPS, State of Charge(SOC), Array Factor.

\section{INTRODUCTION}

This paper will discuss the technical and economic aspects of uninterrupted power supply systems to factories, hospitals, workshops ,....etc. There is a worldwide need to reduce the amount of energy consumption, and everybody has his part to play, whether in industry, transport, business, construction, or at home. Consuming less energy and being more efficient in the way people run their homes will naturally save money and protect the environment as well. At the same time, it will help protect the environment[6]. The power interruption is a problem associated with the AC power supplied by the utility company. In many cases, electricity is needed in emergency situations[2]. The integration of renewable energy source such as solar energy can help provide uninterruptible power supply, but in many other cases the solar energy is not enough to provide all energy needed to the critical loads so we can use a hybrid system using a diesel generator combined with PV to supply a critical load[4]. The design of PV systems depends on the available solar energy at the site and the load demand[1].

\section{PV SYSTEM}

The PV array is composed of PV modules arranged in parallel and series[1]. The PV modules convert solar energy that taken from the sun to electrical energy that can be used in any loads [7]. The PV panels produce direct current so it must be connected with inverter to invert DC into AC to connect to the grid. The current voltage equation of the PV modules is given by[7]:

$$
I_{m p}=I_{p h}-I_{o}\left(e^{\frac{V_{m p}}{V_{T}}}-1\right)
$$

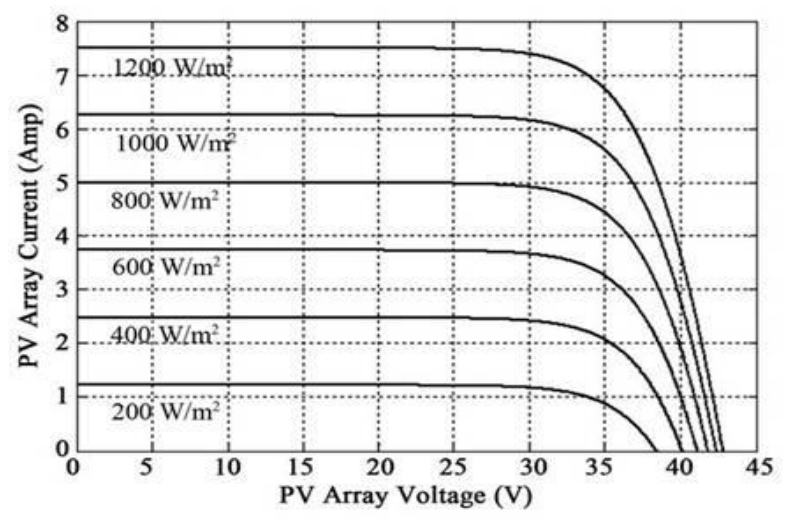

Fig 1: I-V Characteristics of PV modules

$V_{T}=\frac{K T}{q}$

The power output of solar cell is given by:

$$
P_{m p}=I_{m p} * V_{m p}
$$

$\mathrm{V}_{\mathrm{mp}}=$ Max power voltage of PV array (V);

$\mathrm{P}_{\mathrm{mp}}=$ Output power of PV array (W);

$\mathrm{I}_{\mathrm{mp}}=$ Max power current of PV array (A);

$\mathrm{T}=$ Cell temperature $(\mathrm{K})$;

$\mathrm{q}=$ Electron charge $=1.6 \times 10-19(\mathrm{C})$;

$\mathrm{I}_{\mathrm{ph}}=$ Photo current (A);

$\mathrm{K}=$ Boltzman constant=1.38x10-23(J/K);

$\mathrm{I}_{0}=$ Array reverse saturation current (A); 


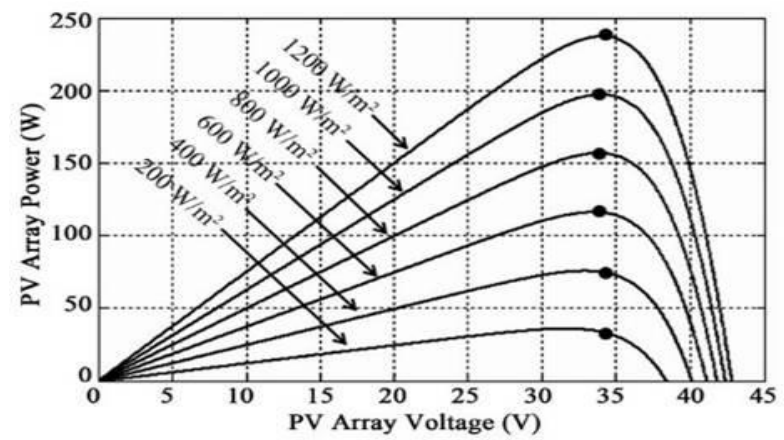

Fig 2: P-V Characteristics of PV modules

The array factor $F_{L}$ is defined by Eq.(4) as the ratio between $\mathrm{PV}$ array peak power $\mathrm{P}_{\mathrm{p}}$ and the average load power $\overline{\mathrm{PL}}$ as given by[7]:

$$
F_{L}=\frac{P_{P}}{\overline{P_{L}}}
$$

To compare the alternative design, on an economical basis, the Economic analysis will be discussed now.

\section{ECONOMIC ANALYSIS}

\subsection{Economic Present Value Analysis}

There are two methods of payment uniform and geometric gradient payments[8].

\subsubsection{Uniform payments}

All installments of payment are equal

- $\quad \mathrm{P}$ is (Initial payment at starting moment),

- A is (an Installment of payment),

- $\mathrm{i}$ is (annual interest rate and $\mathrm{N}$ is the number of Installments).

If there is one deposited an amount A in the bank with annual interested rate, then the amount to be paid by the bank after one year is [8]:

$$
F=A(1+i)
$$

Where:

$\mathrm{F}$ is the future value

If the payment by the bank after $\mathrm{N}$ year is given by:

$$
F=A(1+i)^{N}(6)
$$

There is a case which has deposited a sum P now and gets that amount, including interest in the form of a series amounts each over one year now equals $\mathrm{P}$ is given by:

$$
P=\frac{A}{(1+i)}(7)
$$

$\mathrm{A} /(1+\mathrm{i}) 2$ is the amount $\mathrm{A}$ after two years present value $\mathrm{A} /(1+\mathrm{i}) 3$ the amount $\mathrm{A}$ after three years present value The amount A after $\mathrm{N}$ year's present value is given by:
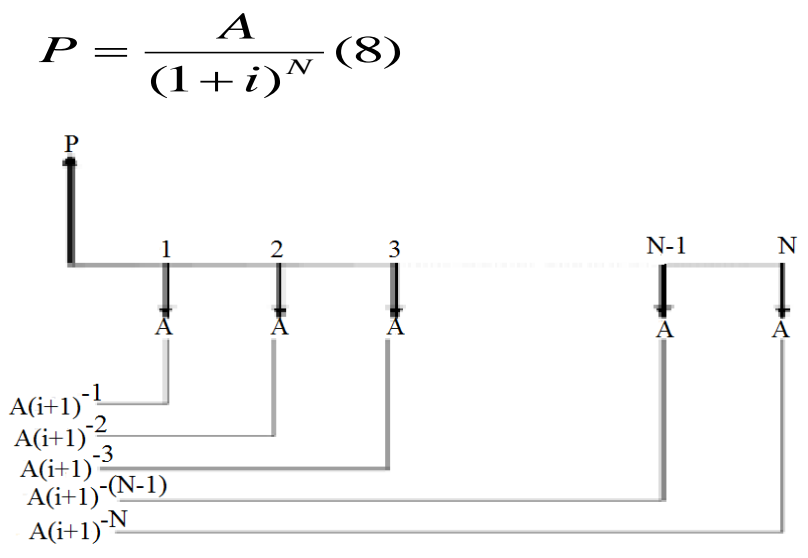

Fig 3: Payment flow

In Fig.3the present value of each amount payment. A for uniform payment method.

Where

- $\quad \mathrm{N}$ is the number of Installments periods.

The sum amount $\mathrm{A}$ of uniform series is as following:

$$
P=\frac{A}{1+i}+\frac{A}{(1+i)^{2}}+\ldots+\frac{A}{(1+i)^{N}}
$$

By multiplying both sides by $(1+i)$ that lead to the following equation.

$$
P(1+i)=A+\frac{A}{1+i}+\frac{A}{(1+i)^{2}}+\ldots . .+\frac{A}{(1+i)^{N-1}}(10)
$$

The Eq.(10) valid if only all the following conditions are achieved:

1-The first payment is paid after one period from the start calculating moment for $\mathrm{P}[9]$.

2-The payments are equal.

3-The periods between payments are equal

From (8) and (9) it will lead to the following equation.

$$
P=A *\left[\frac{1-(1+i)^{-N}}{i}\right](11)
$$

\subsubsection{Geometric series payments}

All installments of payment are increasing or decreasing with a constant rate of $\mathrm{g}$ every period with and $\mathrm{A}$ is the first amount of payment [9].

$\mathrm{A}(\mathrm{g}+1) /(1+\mathrm{i})^{2}$ the amount of payment after two years equal value and $\mathrm{A}(\mathrm{g}+1) 2 /(1+\mathrm{i})^{3}$ is the amount of payment after three years present value and so on. The amount of payment(p) after $\mathrm{N}$ year's present value is given by:

$$
P=\frac{A *(1+g)^{N-1}}{(1+i)^{N}}(12)
$$




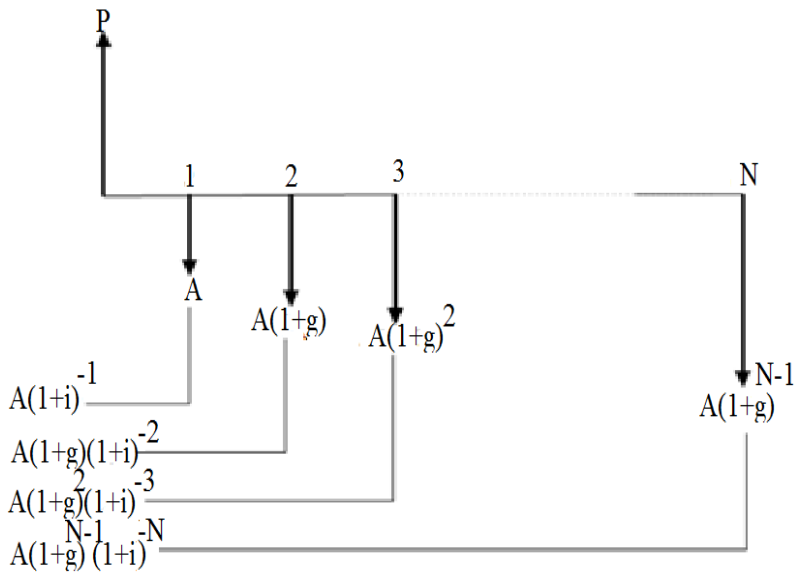

Fig 4: Geometric series payment cash flow

In Fig.4the present value of each amount of payment for Arithmetic gradient payment method[8].

Where:

$\mathrm{N}$ is the number of Installments period.

The amount of payments for geometric series is given by:

$P=\frac{A}{(1+i)}+\frac{A(1+g)}{(1+i)^{2}}+\ldots .+\frac{A(1+g)^{2}}{(1+i)^{3}}+\frac{A(1+g)^{N-1}}{(1+i)^{N}}$

By multiplying both sides of Eq.(12) by: $\frac{(1+g)}{(1+i)}$

It will lead to the following equation:

$$
\frac{P(1+g)}{(1+i)}=\frac{A(1+g)}{(1+i)^{2}}+\frac{A(1+g)^{2}}{(1+i)^{3}}+\ldots \ldots .+\frac{A(1+g)^{N}}{(1+i)^{N+1}}(14)
$$

From (13) and (14) these equations will lead to the following equation.

$$
P_{t}=A\left[\frac{1-\left(\frac{1+g}{1+i}\right)^{N}}{i-g}\right](15)
$$

Note, if $\mathrm{g}=0$ Eq.(14) become

$$
\begin{gathered}
P=A *\left[\frac{1-(1+i)^{-N}}{i}\right](16) \\
\text { if } \mathrm{i}=\mathrm{g} \\
P=\frac{N * A}{1+i}(17)
\end{gathered}
$$

from the equation(15) we find that:

$$
E_{25 y}=E_{0}\left[\frac{1-\left(\frac{1+g}{1+i}\right)^{N}}{i-g}\right](18)
$$

$$
\begin{gathered}
\text { if } \quad \mathrm{i}=\mathrm{g} \\
E_{25 y}=E_{0}\left[\frac{N}{1+i}\right](19) \\
C_{0}=\left[\frac{P_{t}}{E_{25 y}}\right](20)
\end{gathered}
$$

Where:

$\mathrm{i}=$ annual interest rate

$E_{25 y}=$ Total generated energy over 25 years $(\mathrm{kWh})$.

$\mathrm{N}=$ number of Installment

$\mathrm{C}_{0}=$ Selling price per $\mathrm{kWh}$.

$\mathrm{P}_{\mathrm{t}}=$ Total system cost over 25 years.

$\mathrm{E}_{0}=$ Initial generated energy $(\mathrm{kWh})$.

Note the Eq.(16) valid if only all the next points are achieved:

A-The first payment is paid after one period from the start calculating moment for $\mathrm{P}[9]$.

B-The payments are increasing or decreasing with fixed rates.

$\mathrm{C}$-The periods between payments are equal.

So in our cases we use equation (16) because $\mathrm{i}=\mathrm{g}$ In all systems the yearly annual loan equal $2 \%$. The yearly loss in PV efficiency systems equal $2 \%$.

\section{UNINTERRUPTIPLE POWER SUPPLY SYSTEMS FOR REMOTE AREAS}

These systems operate in a place where there is no grid utility and it will be explained as following.

\subsection{Hybrid PV and Generator System (AC and DC load)}

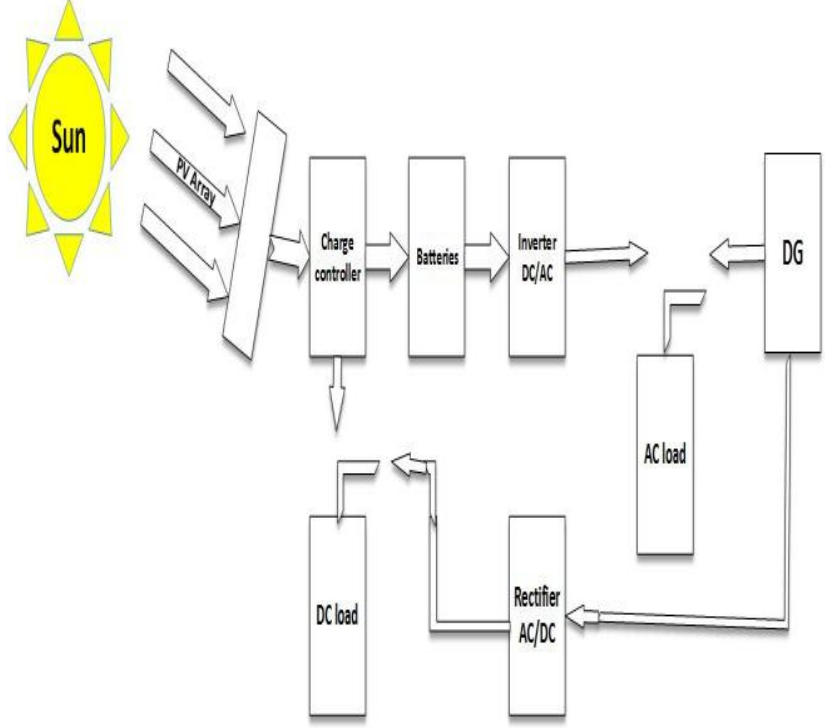

Fig 5: Structure of Hybrid PV and generator system

In this system the loads are using two types of energy sources solar and generator. At day the loads are using solar energy source. And at night and cloudy days loads are using 
generator energy source[7]. PV and a battery bank provides the opportunity to supply a part of load for many hours overnight using a battery system[3]. If the load is AC load the system will use DC to AC inverter after PV modules and if the load is dc load the system will use AC to Dc rectifier after diesel generator[4]. So the load have a switch to shows between the rectifier and the charge controller[10].

- Advantages:

1- No interruption period .

2-Acceptable Reliability

- Disadvantages:

1- Costly because it needs fuel and maintenance[5].

2- Complicated.

By using MATLAB simulation Fig.6 shows load energy, diesel energy, PV array energy as well as PV plus diesel energy versus months. It is noted that PV plus diesel energy exceeds load energy most of the year except in winter months where PV plus diesel slightly exceeds load energy. Array factor is shown in Fig.7.

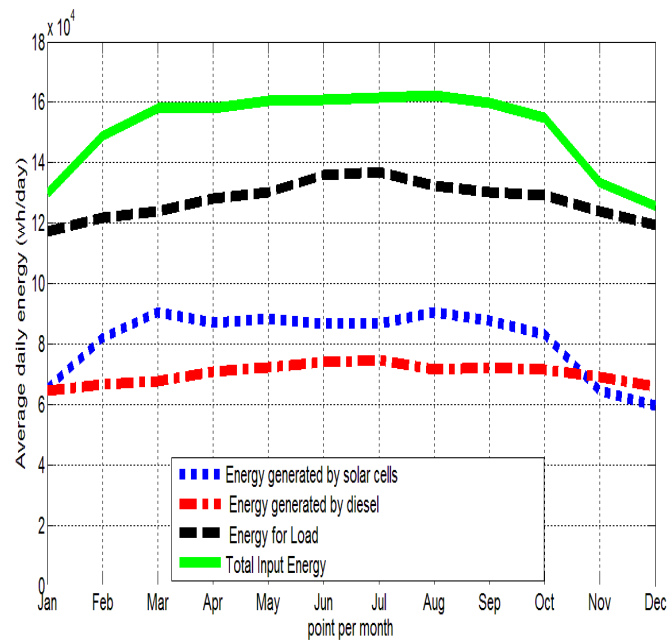

Fig 6: average daily energy for Hybrid PV and generator system per month

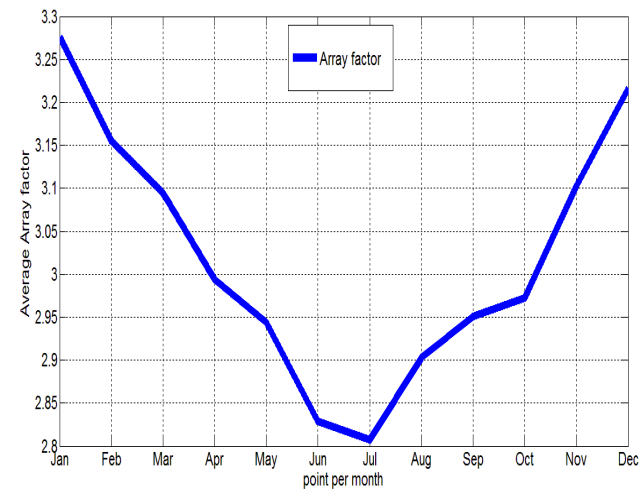

Fig 7: Array factor for Hybrid PV and generator System per month

\subsubsection{Economic analysis for Hybrid PV and generator system (AC and DC load)}

By adding little amount of storage battery strings to operating the loads in the period between switching between the both energy sources. Although these battery strings worked as a backup for max four hours and because of the maintenance of Generators need to maintenance several times[3].

In this case the average load power is $5.25 \mathrm{~kW}$.Using MATLAB as a simulation program to compute the array size as well as diesel generator .Size showed that the number of parallel photovoltaic panels are 40 modules and two series panels. In this system all loads are operated at $50 \mathrm{~V} \mathrm{DC}$ so photovoltaic panels in this system are connected as a group of two series panels and all groups are connected parallel with each other to produce the required energy for the load. The system is using batteries with 500 ampere/hour. The over sizing of diesel generator is needed to cover the needing of energy if there were cloudy days[7]. The economic analysis is shown in Sec. (3).

In this case equation (19) will be used to find E25y then equation (20) will be used with the following values to find Co.

- $\mathrm{Pt}=126455 \$$,

- Average load Power $(\mathrm{pl})=5.25 \mathrm{~kW}$,

- $\quad$ PV modules and its supports $=24,000 \$$,

- PV array size $=16 \mathrm{kWp}$,

- Batteries size $=500 \mathrm{AH}$,

- $\quad$ Array factor $=3.04$,

- DG capacity= $10 \mathrm{kva}$,

- Initial DG\& ATS cost=2,738 \$,

- Total DG\& ATS cost=86,231 \$,

- Initial batteries cost=2,625 \$,

- Total batteries cost $=16,223 \$$,

- $\quad$ Total system $\cos t=126,455 \$$,

- $\quad E 25 \mathrm{y}=1127206 \mathrm{kWh}$.

- $\mathrm{Co}=0.11 \$ / \mathrm{kWh}$ 


\subsection{PV Stand-Alone System(AC and DC load)}

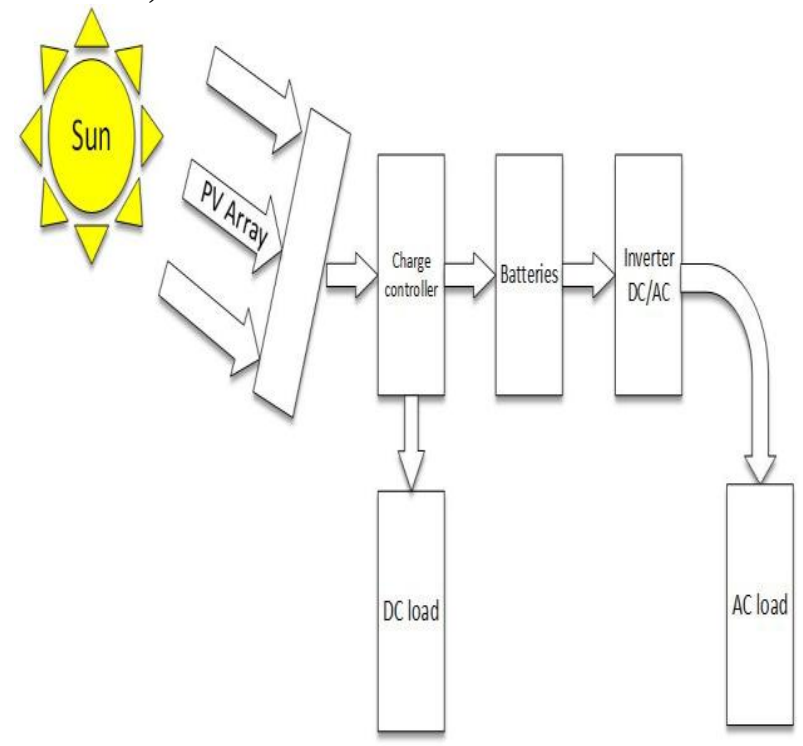

Fig 8: Structure of stand-alone system

During the day the solar energy source which is generated from the sun operates the load and charges the batteries. At night and at cloudy days solar energy source is unavailable, so that this system depends on the batteries[6] .The battery string size is very large to cover all night and one cloudy day. The stand-alone system is a combination of solar-PV array modules and batteries as shown in fig (6) which generates direct current (DC). DC line which provide all DC sources to the charge controller, which control charging and discharging the battery string and to provide DC loads. For AC loads the system will use DC to AC inverter to provide the load with AC current[10].

By using MATLAB as a simulation program. Fig.9 shows load energy as well as energy generated by a solar cell versus months. It is noted that PV energy exceeds load energy most of the year except in winter months where PV energy slightly exceeds load energy[6]. SOC of the batteries string during the year is shown in Fig.10. The array factor curve is shown in Fig.11.

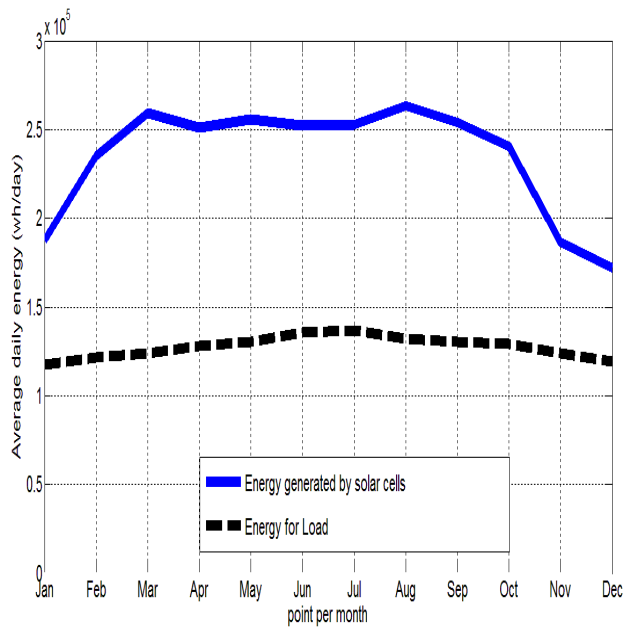

Fig 9: Average daily energy for Stand-Alone system per month

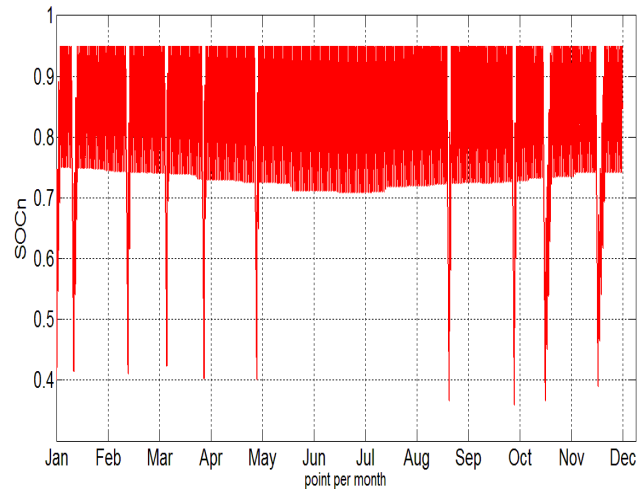

Fig 10: SOC for Stand-Alone system per month

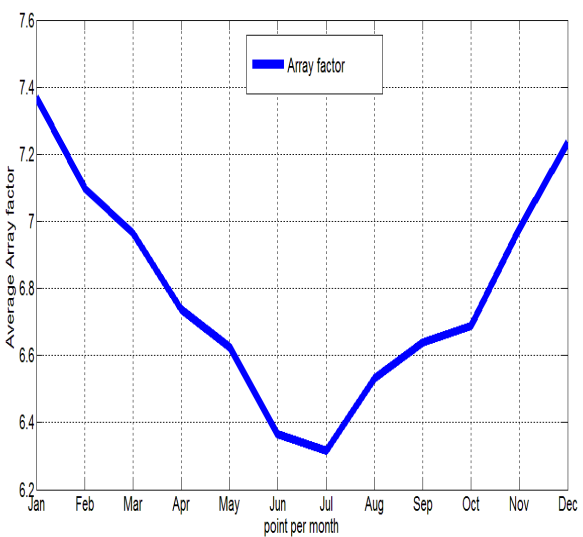

Fig 11: Array factor for Stand-Alone system per month

- Advantages:

1. Have not interruption period.

2. Slightly complicated and good reliability.

- Disadvantages:

1. Have only one source for electricity.

2. The cost proportional to the battery size and the battery size Depending on loads and the number of cloudy days.

As shown in Fig.10 ripples in curve present the cloudy days. So cloudy days make the SOC decrease to $20 \%$ due to discharge operation[4].

Then due to charging operation it is increasing to $90 \%$.there is a gap between the solar energy generated by PV system and the energy to operate the load that because the power loss in charging and discharging the battery string also in case of the next day is may be cloudy[2].

\subsubsection{Economic analysis for PV Stand-Alone system ( $A C$ and DC load)}

It use large number of PV array modules and batteries so this system can operate load for 48 hours. The SOC of the batteries in the range of $20 \%$ to $90 \%$ to save the battery life and that between 2-3 years[4]. In this system have aluminum plates, PV solar modules, to fixe PV solar modules, Batteries strings. The average load power is $5.25 \mathrm{~kW}$. Detailed simulation program using math-lab is used to compute the array size as well as battery size. Size showed that the number of parallel photovoltaic panels is 110 modules and two series 
panels. In this system all loads are operated at $50 \mathrm{~V} \mathrm{DC}$ so photovoltaic panels in this system is connected as group of two series panels and all groups are connected parallel with each other to produce the required energy for the load. The system will use batteries with 7500 ampere/hour. The over sizing of batteries is needed to cover the needing of energy if there were cloudy days[7]. The economic analysis is shown in Sec.(3).

In this case equation (19) will be used to findE25y then we will use equation (20) using the following values to find Co

- $\mathrm{Pt}=309354 \$$,

- Average load Power(pl) $=5.25 \mathrm{~kW}$,

- $\quad$ PV array size $=44 \mathrm{kWp}$,

- Batteries size $=7500 \mathrm{AH}$,

- $\quad$ Array factor $=8.38$,

- Initial batteries cost=39,395 \$,

- Total batteries cost $=243,354$,

- Total system cost $=309,354 \$$,

- $\quad \mathrm{E} 25 \mathrm{y}=1127206 \mathrm{kWh}$,

- $\mathrm{Co}=0.274 \$ / \mathrm{kWh}$

\subsection{Stand-Alone and Generator Running at Cloudy Days System (AC and DC load)}

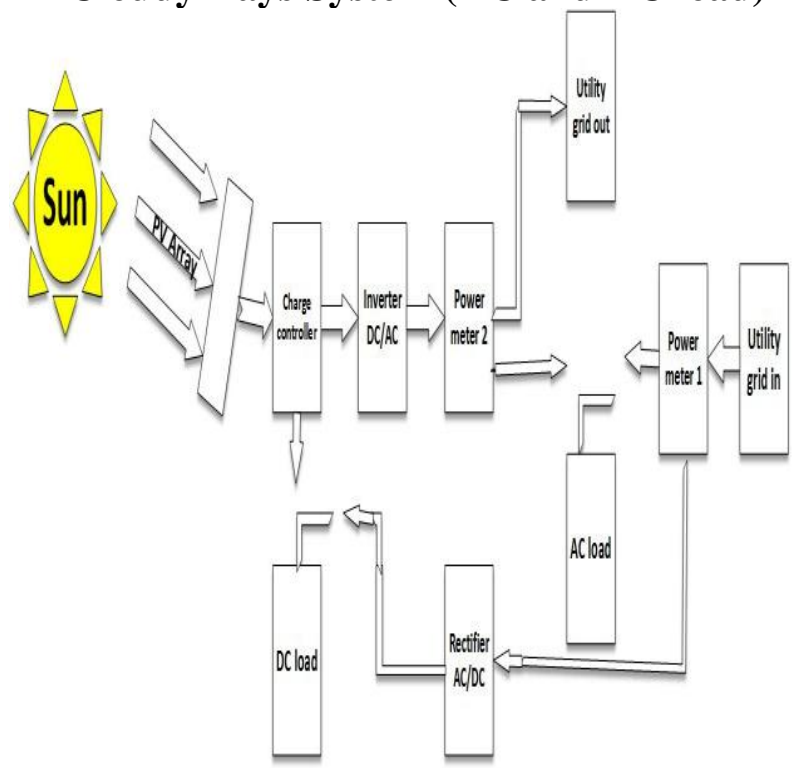

Fig 12: The Structure of Stand-alone and generator running on the cloudy days system

The system is a combination of solar PV array modules which generating direct current (DC), generator energy source which generating alternated current (AC) when cloudy day is exist. So when the loads are AC loads we take the DC current from $\mathrm{PV}$ modules to inverter to convert it from (DC)current to AC current and in cloudy days the AC current will be taken from generator direct to the load[4]. In case of dc load (DC) current will be taken from PV modules direct to the load and in cloudy days (AC) current will be taken from generator to rectifier to change the current from (AC) to (DC) current [4].

By using MATLAB as a simulation program. Fig.13 shows load energy, diesel energy as well as PV array energy versus months. It is noted that PV energy exceeds load energy most of the year except at winter months where PV slightly exceeds load energy. SOC of battery string during the year is showed in Fig.14. Array factor curve is shown in Fig.15

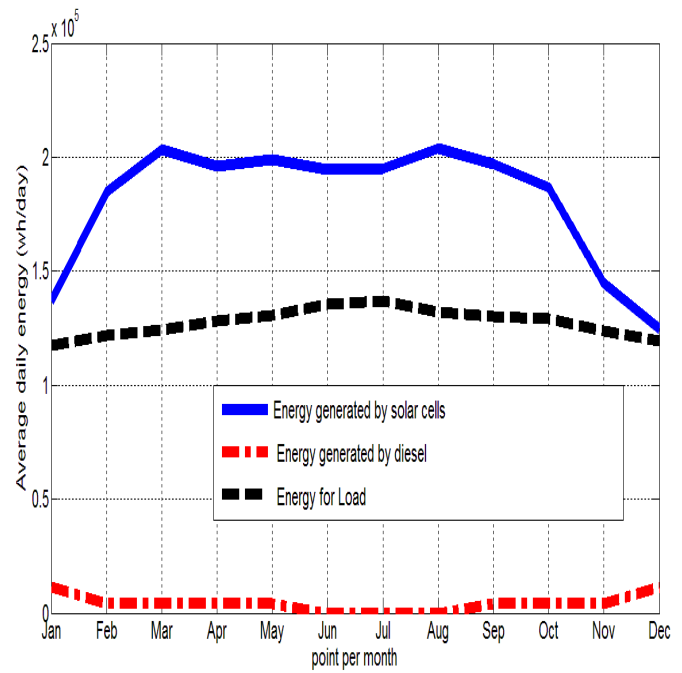

Fig 13: Average daily energy for Stand-alone and generator running on the cloudy days system per month

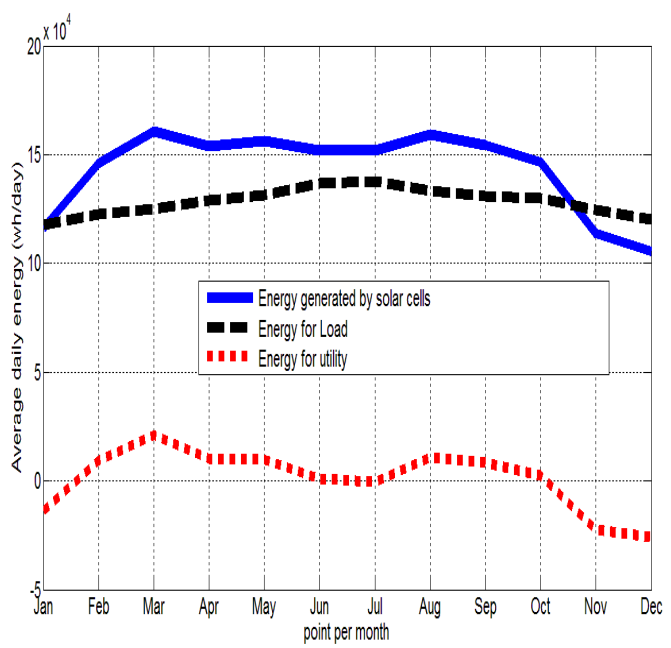

Fig 14: Array factor for Stand-alone and generator running on the cloudy days system per month

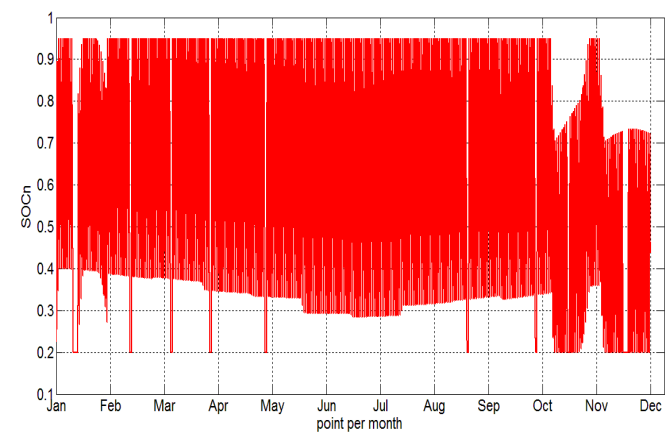

Fig 15: SOC Stand-alone and generator running on the cloudy days system per month 
Advantage:

1. The storage of batteries strings decreases by half than stand-alone system.

2. Generator running for a few days that less the expensive on fuel, maintenance and no needed for changing the generator[5].

Disadvantage:

1- High cost comparing with on grid connected systems.

\subsubsection{Economic analysis for Stand-alone and} generator running on the cloudy days system(AC and DC load)

The battery strings are decreased more than a stand-alone system that decreasing the cost of the system. The battery storage size is operating the loads during the year with SOC ratio between $20 \%$ to $90 \%$. The average load power is $5.25 \mathrm{~kW}$. Using MATLAB as a simulation program to compute the array size as well as diesel generator. Size showed that the number of parallel photovoltaic panels is 90 module and two series panels. In this system all loads are operated at $50 \mathrm{~V} \mathrm{DC}$ so photovoltaic panels in this system are connected as group of two series panels and all groups are connected parallel with each other to produce the required energy to the load. We will use batteries with 2800 ampere/hour. The over sizing of diesel generator is needed to cover the needing of energy if there were cloudy days[7].the economic analysis is shown in Sec. (3).

In this case equation (19) will be used to find E25y then equation (20) will be used with the following values to find Co

- $\mathrm{P}_{\mathrm{t}}=231083 \$$.

- Average load Power $(\mathrm{pl})=5.25 \mathrm{~kW}$,

- $\quad$ PV modules and its supports $=54,000 \$ \$$,

- $\quad$ PV array size $=36 \mathrm{kWp}$,

- Batteries size $=2800 \mathrm{AH}$,

- Array factor $=6.85$,

- DG capacity $=10 \mathrm{KVA}$,

- Initial DG\& ATS cost=2,738\$,

- Total DG\& ATS cost $=86,231 \$$,

- Initial batteries cost=14,700\$,

- Total batteries cost $=90,852 \$$,

- Total system cost $=231,083 \$$,

- $\mathrm{E}_{25 \mathrm{y}}=1127206 \mathrm{kWh}$,

- $\mathrm{C}_{0}=0.205 \$ / \mathrm{kWh}$

\section{UNINTRRUPTIPLE POWER SUPPLY SYSTEMS FOR URBAN AREAS}

These systems are the systems that will depend on the grid electricity and it will be explained as follows.

\subsection{On grid PV system (AC and DC load)}

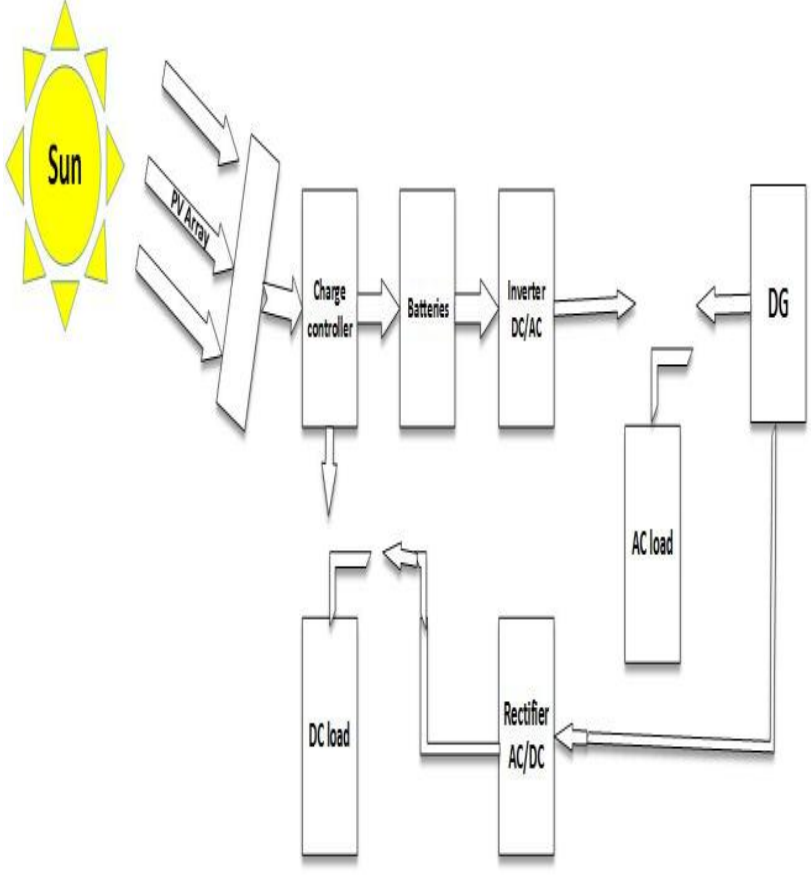

Fig 16: Structure on grid PV system

The system is working by using two electrical energy sources from PV energy source and grid utility. During the morning the load is using PV energy source except the time of sunrise and sunset the load is using the electrical grid and also during the night PV is not working because there is no solar energy is available at night so the load is using the electrical grid[7]. This system has low batteries that can working for max 3 hours.

The on grid PV system is a combination of utility electric grid energy source which generating alternating current (AC) solar-PV array modules which generating direct current (DC). when PV energy unavailable. So for AC loads it will work after inverter to convert (DC) current into (AC) current and for DC loads it will work without needing to inverter and the inverter will be used for providing (AC) current to the grid. When the loads needs for electricity from the grid, there are two cases the first one is that if the load is AC load it will take the (AC) current from the grid and the second case is that if the load is (DC) load it will need to rectifier after the (AC) current that come from the grid to provide (DC) current to the $\operatorname{load}[10]$

By using MATLAB as a simulation program. Fig.17 shows load energy, utility energy as well as PV array energy versus months. It is noted that PV energy exceeds load energy most of the year except in winter months where PV slightly exceeds load energy. If the curve of utility energy is less than zero it means that the system will take the needed energy from the grid. If the curve of utility energy is more than zero it means that the system will provide energy to the grid. The array factor curve shown in Fig. 18. 


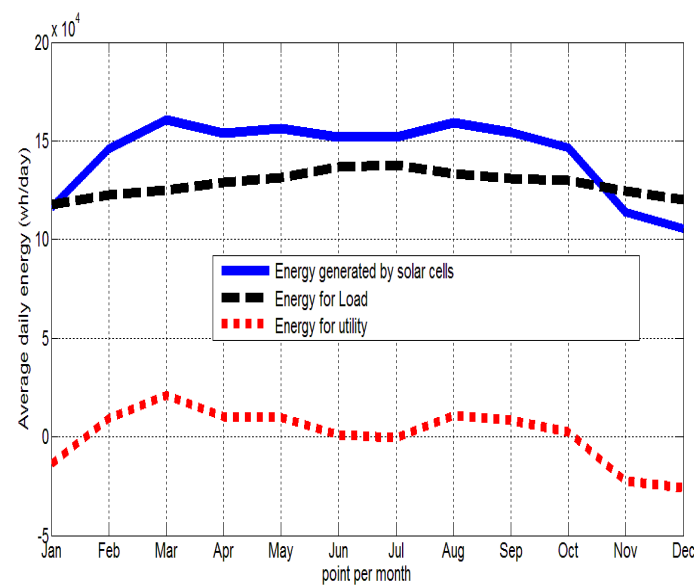

Fig 17: Monthly average daily energy for gird PV system

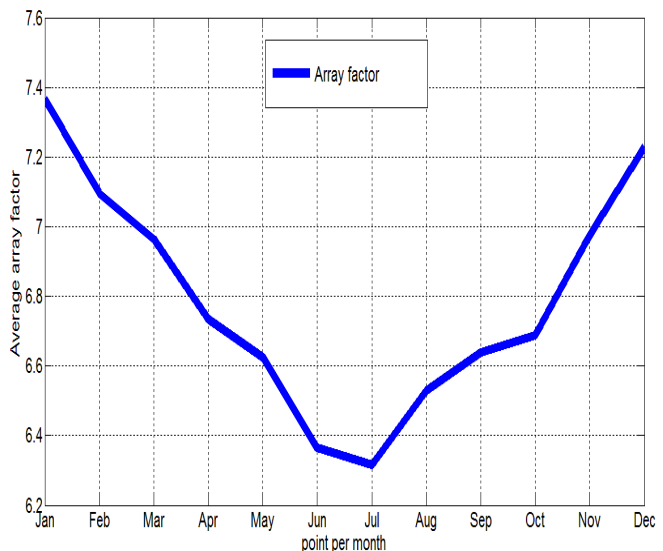

Fig 18: Array factor per month for gird PV system

Advantage:

1. Not costly

2. Have not interruption period

3. Slightly complicated and good reliability

Disadvantage:

1- the system can't be depended on it all the time specially in cloudy days and night. So this system can't be applied in remote areas.

\subsubsection{Economic analysis on gird PV system (AC and DC load)}

This system is using a large number of PV array modules to sell the exceeding energy to the grid and buy the electrical energy from the grid at night with the same cost which sold to the grid[8]. The high cost in this system is in the initial cost. Batteries in the system works, if the electrical energy source or PV solar energy source was down for max 3 hours. The average load power is $5.25 \mathrm{~kW}$.Detailed simulation program using MATLAB is used to compute the array size, the energy that will be provided to the grid as well as the energy needed to the load from the grid. Size showed that the number of parallel photovoltaic panels is 70 modules and two series panels. In this system all loads are operated at $50 \mathrm{~V} \mathrm{DC}$ so photovoltaic panels in this system are connected as a group of two series panels and all groups are connected parallel with each other to produce the required energy to the load. We will use batteries with 240 ampere/hour. The economic analysis is shown in Sec.(3)

In this case equation (19) will be used to find $E_{25 y}$ then equation (20) will be used with the following values to find $\mathrm{C}_{0}$

- $\mathrm{Pt}=58160 \$$,

- Average load Power $(\mathrm{pl})=5.25 \mathrm{~kW}$,

- PV array size $=28 \mathrm{kWp}$,

- Batteries size $=240 \mathrm{AH}$,

- Array factor $=5.33$,

- Initial batteries cost=1260 \$,

- Total batteries cost $=7,787 \$$,

- Total system cost $=58,160 \$$,

- $\quad \mathrm{E} 25 \mathrm{y}=735294 \mathrm{kWh}$.

- PV modules and its supports $=42,000 \quad \$$, Initial inverter and cables cost $=5,600 \quad \$$, Total inverter and cables cost $=8,372 \quad \$$, $\mathrm{Co}=0.087 \$ / \mathrm{kWh}$

\section{CONCLUSION}

- The systems in this paper are useful in the future because these systems are using clean fuel (solar energy) and it is a renewable energy and cheap. So we can depend on it because the renewable energy can be found easier than other fuels.

- For urban areas, the optimum economic solution to loads is a hybrid system consists of PV system and grid utility. For remote areas the optimum economic solution is the hybrid PV and generator and the cost per kWh for every system will be shown as following:

1. On grid PV system cost(the best using in urban area $)=$ $0.087 \$ / \mathrm{kWh}$.

2. Hybrid PV and generator system cost(the best using in remote area) $=0.112 \$ / \mathrm{kWh}$.

3. Stand-alone and generator running at cloudy days system cost $=0.205 \$ / \mathrm{kWh}$

4. Stand-Alone system cost $=0.274 \$ / \mathrm{kWh}$.

\section{REFERENCES}

[1] DikeU.Ike,AnthonyU.AdogheandAdemolaAbdulkareem "Analysis Of Telecom Base stations Powered By Solar Energy", INTERNATIONAL JOURNAL OF SCIENTIFIC \& TECHNOLOGY RESEARCH .,Vol. 3,pp. 369-374, April 2014.

[2] S. Jayasimha and T.P. KumarSignion SystemsLtd.71\&72, Anrich Industrial Estate, IDA Bollaram Medak District, A.P., India 502325

[3] PragyaNema, "Noble approach of power feeding for cellular mobile telephony base station site: Hybrid energy system.", International Journal of Energy and power Engineering, Vol. 3 , No. 6-2, pp. 7-14,2014.

[4] Ajay Sharma,Anand Singh and Manish Khemariya "Homer Optimization Based Solar PV; Wind Energy and Diesel Generator Based Hybrid System.",International Journal of Soft Computing and Engineering (IJSCE), Vol.3,pp.199-204 March2013. 
[5] Denver,"Maintenance Scheduling for Mechanical Equipment", U.S Department Bureau of Reclamation, Facilities Instructions standards and Techniques,Vol.41A,Jan 2009.

[6] Tiwari, GopalNath and SwapnilDubey. 2010, "Fundamentals of photovoltaic modules and their applications", No. 2 Royal Society of Chemistry.

[7] AnisWagdy R. 1985,"Design of photovoltaic systems for tropical climates", Ph.D. thesis, catholic university of loavain, Belgium, Solar cells15, no. 1.
[8] L.Blank and A.Tarquin "Engineering Economics" McGraw Hill,New York 2005.

[9] W.G.Sullivan, J.Bontaelli and E.Wicks"Engineering Economy "Printic Hall,New Jersey 2000.

[10] Angelo A. Beltran Jr. and Felicito S. Caluyo Design and Implementation of Fuzzy Logic Controlled Uninterruptible Power Supply Integrating Renewable Solar Energy International Journal of Engineering Research Volume No.3, Issue No.3, pp : 162-166 01 March 2014. 